\title{
Restoring assembly and activity of cystathionine $\beta$-synthase mutants by ligands and chemical chaperones
}

\author{
Jana Kopecká • Jakub Krijt • Kateřina Raková • \\ Viktor Kožich
}

Received: 22 December 2009/Revised: 28 February 2010 / Accepted: 19 March 2010/Published online: 20 May 2010

(C) The Author(s) 2010. This article is published with open access at Springerlink.com

\begin{abstract}
Misfolding and aggregation of mutant enzymes have been proposed to play role in the pathogenesis of homocystinuria due to cystathionine $\beta$-synthase (CBS) deficiency. Chemical chaperones have been recently shown to facilitate proper assembly of several CBS mutants. To asses the number of patients that may respond to chaperone therapy, we examined the effect of selected CBS ligands and osmolytes on assembly and activity of 27 CBS mutants that represent $70 \%$ of known CBS alleles. The mutant enzymes were expressed in a bacterial system, and their properties were assessed by native Western blotting and sensitive liquid chromatography tandem mass spectrometry (LC-MS/MS) assay, respectively. We studied the chaperoning activity of $\delta$-aminolevulinic acid $(\delta$-ALA) - a heme precursor - and of three osmolytes betaine, 2-aminoethanesulfonic acid (taurine), and glycerol. Fourteen mutants responded by at least $30 \%$ increase in the amount of correctly assembled tetramers and enzymatic activity to the
\end{abstract}

Presented at the 7th International Conference on Homocysteine Metabolism, Prague, 21-25 June 2009

Communicated by: Niels Gregersen

References to electronic databases: http://www.chem.qmul.ac.uk/ iubmb/enzyme/EC4/2/1/22.html: http://www.ncbi.nlm.nih.gov/entrez/ dispomim.cgi?id=236200: http://www.uchsc.edu/cbs

Competing interest: None declared.

Electronic supplementary material The online version of this article (doi:10.1007/s10545-010-9087-5) contains supplementary material, which is available to authorized users.

J. Kopecká $\cdot$ J. Krijt $\cdot$ K. Raková $\cdot$ V. Kožich $(\bowtie)$

Institute of Inherited Metabolic Disorders,

First Faculty of Medicine, Charles University in Prague and

General University Hospital in Prague,

Ke Karlovu 2,

12808 Praha 2, Czech Republic

e-mail: Viktor.Kozich@LF1.CUNI.CZ coexpressional presence of either $0.5 \mathrm{mM} \delta$-ALA, $100 \mathrm{mM}$ betaine, and/or $750 \mathrm{mM}$ glycerol. Eight of these mutants (p.R266K, p.P49L, p.R125Q, p.K102N, p.R369C, p.V180A, p.P78R, p.S466L) were rescuable by all of these three substances. Four mutants showed increased formation of tetramers that was not accompanied by changes in activity. Topology of mutations appeared to determine the chaperone responsiveness, as 11 of 14 solvent-exposed mutations were substantially more responsive than three of 13 buried mutations. This study identified chaperone-responsive mutants that represent 56 of 713 known patient-derived CBS alleles and may serve as a basis for exploring pharmacological approaches aimed at correcting misfolding in homocystinuria.
Abbreviations
$\delta$-ALA $\delta$-aminolevulinic acid
CBS Cystathionine $\beta$-synthase
SAM S-adenosyl-L-methionine

\section{Introduction}

Misfolding of mutant proteins plays a role in the pathogenesis of many human genetic diseases. These so-called conformational disorders are characterized by decreased stability, aggregation, impaired trafficking, and accumulation of misfolded proteins. It should be noted that misfolding is an important mechanism not only in rare genetic conditions but has been also implicated in common diseases such as diabetes mellitus type 2 (Hayden et al. 2005), Alzheimer's disease (Agorogiannis et al. 2004), Parkinson's disease (Agorogiannis et al. 2004) and others. In recent years, chemical or pharmacological chaperones have been reported as a therapeutic option to prevent 
misfolding or aberrant trafficking of proteins involved in human conformational diseases (Perlmutter 2002). Chemical chaperones are low molecular weight substancesusually osmolytes - that protect proteins against various denaturing conditions via a solvophobic thermodynamic force resulting from interactions between the osmolyte and the peptide backbone (Bolen and Baskakov 2001). Whereas chemical chaperones facilitate folding of many proteins nonspecifically at relatively high concentrations, pharmacological chaperones exhibit specific effects on particular proteins, and their efficient concentrations are much lower. Pharmacological chaperones are protein ligands such as substrates, inhibitors, or similar compounds (Arakawa et al. 2006; Perlmutter 2002) that minimize aggregation by assisting the target mutant proteins to fold properly and/or in transporting them to the extracellular space. Pharmacological chaperones are being used to treat conditions such as lysosomal storage disorders (Pastores and Sathe 2006).

Cystathionine $\beta$-synthase (CBS; EC 4.2.1.22) (http:// www.chem.qmul.ac.uk/iubmb/enzyme/EC4/2/1/22.html) is a homotetrameric cytosolic enzyme that channels the potentially toxic sulfur amino acid homocysteine through the transsulfuration pathway. In addition to its two substrates - serine and homocysteine-CBS binds also two cofactors - pyridoxal-5-phosphate and heme (Kery et al. 1994; Skovby et al. 1984), the role of which in CBS folding has been discussed in several previous studies (Janosik et al. 2001b; Majtan et al. 2008). Each subunit of the full-length $63-\mathrm{kDa}$ enzyme is composed of the $\mathrm{N}$ terminal heme-binding domain, highly conserved catalytic domain, and the C-terminal regulatory domain that binds the allosteric activator S-adenosyl-L-methionine (SAM) (Janosik et al. 2001a). So far, 3D structure of only the truncated form of CBS has been solved (Meier et al. 2001). This $45-\mathrm{kDa}$ form lacks $\mathrm{C}$-terminal domain, forms dimers instead of tetramers, and is about twice as active as the fulllength enzyme (Kery et al. 1998).

Classical homocystinuria (http://www.ncbi.nlm.nih.gov/ entrez/dispomim.cgi?id=236200) is an autosomal recessive disorder caused by mutations in the $C B S$ gene. With the worldwide prevalence of 1:344,000 (Mudd et al. 2001), CBS deficiency is the most common clinically relevant disorder of sulfur amino acid metabolism. Molecular epidemiological studies indicate that the true incidence may be about 20 times higher (Gaustadnes et al. 1999; Janosik et al. 2009; Refsum et al. 2004). To date, analysis of 713 patient-derived CBS alleles has revealed 154 different mutations (http://www.uchsc.edu/cbs). Misassembly and aggregation of CBS mutants contribute substantially to the pathogenesis of CBS deficiency, as many patient-derived CBS mutants expressed in Escherichia coli form decreased the amount of correctly assembled protein
(Janosik et al. 2001b; Kožich et al. 2010). At present the CBS deficiency is usually treated by administration of large doses of vitamin $B_{6}$ combined with methionine restriction, cysteine supplementation, and enhancement of homocysteine remethylation by betaine and folates (Kožich and Kraus 2001). As about $50 \%$ of patients are nonresponsive to vitamin $\mathrm{B}_{6}$ and management of their diet is quite difficult, especially in late-diagnosed patients, new treatment options are highly desirable. Our recent study (Singh et al. 2007) showed that the presence of glycerol, trimethylamine-N-oxide, dimethylsulfoxide, proline, or sorbitol during expression facilitated proper assembly of four CBS mutants expressed in yeasts, and we proposed that chemical chaperones may be useful in treating CBS deficiency. To estimate the proportion of patients that may potentially benefit from chaperone therapy, we studied the effect of three CBS ligands and three osmolytes on assembly and activity of 27 CBS mutants representing $70 \%$ of known CBS alleles.

\section{Methods}

\section{Chemicals}

If not mentioned specifically, all chemicals were purchased from Sigma Aldrich (St. Louis, MO).

\section{CBS mutants}

In a previous study, we selected a series of 27 CBS mutants representing about two thirds of all known patient-derived alleles and reflecting their topology in different CBS domains (Kožich et al. 2010). The set included eight most prevalent mutations (p.R125Q, p.E144K, p.T191M, p. R266K, p.I278T, p.G307S, p.W409_G453del, and p. $\mathrm{D} 444 \mathrm{~N}$ ) having a frequency of at least ten alleles in the CBS Mutation Database and additional 19 less frequent mutations known to be localized in different domains of the CBS protein (Meier et al. 2001; Meier et al. 2003). After selecting the mutants, we performed an in silico analysis with calculation of the solvent-accessible surface area. Based on previously published criteria, we considered mutant residues with absolute and/or relative solvent-accessible surface area $>40 \mathrm{~A}^{2}$ and $9 \%$, respectively, as being solventexposed, whereas the rest of the mutations were considered as being buried in the globule (Mirkovic et al. 2004).

Responsivity of mutants to chemical chaperones

We tested the chaperoning activity of three ligands and three osmolytes: $\delta$-aminolevulinic acid ( $\delta$-ALA) was selected as a precursor of the CBS cofactor heme, Lserine as one of the substrates, SAM as an allosteric 
activator of CBS, betaine is an osmolyte that is also used in homocystinuria to enhance remethylation of homocysteine to methionine, 2-aminoethanesulfonic acid (taurine) as an osmolyte low in CBS-deficient patients, and glycerol as a general chemical chaperone. These six substances were used in an E. coli expression system, and their effect on assembly/oligomerization and catalytic activity of mutants was then examined. Responsivity of the mutants to the chaperones was defined as an increase in the amount of correctly assembled protein and/or of the specific activity of the enzyme by $>30 \%$. This $30 \%$ difference was arbitrarily chosen to safely discriminate the true effect from noise, as the coefficient of variation of the entire expression system using wild-type CBS was 19\% (Kožich et al. 2010). Mutants exhibiting response in the first experiment were expressed once more in an independent experiment.

\section{Toxicity of chemical chaperones for E. coli}

To optimize conditions, we first determined the toxicity of chaperones. Growth of E. coli DH5- $\alpha$ after the addition of chaperones to medium was monitored by measuring optical density at $600 \mathrm{~nm}\left(\mathrm{OD}_{600}\right)$. Chaperones were added at the time of induction $\left(\mathrm{OD}_{600} \sim 0.5-0.6\right)$ in two different concentrations: $50 \mathrm{mM}$ and $100 \mathrm{mM}$ L-serine, $0.5 \mathrm{mM}$ and $1 \mathrm{mM} \mathrm{SAM}, 0.5 \mathrm{mM}$ and $1.5 \mathrm{mM} \delta$-ALA, $50 \mathrm{mM}$ and $100 \mathrm{mM}$ betaine, $25 \mathrm{mM}$ and $50 \mathrm{mM}$ taurine, and $750 \mathrm{mM}$ and $1,000 \mathrm{mM}$ glycerol, respectively. No significant inhibition of $E$. coli growth was observed after 4-h expression in the presence of these substances in the medium, with the exception of 1,000 mM glycerol (see Supplementary Table 1). Based on these experiments, we selected optimal chaperone concentrations as follows: $100 \mathrm{mM}$ L-serine, $1 \mathrm{mM}$ SAM, $0.5 \mathrm{mM} \delta$-ALA, $100 \mathrm{mM}$ betaine, $50 \mathrm{mM}$ taurine, and $750 \mathrm{mM}$ glycerol.

Intracellular chaperones concentrations

In the next step, we examined the efficiency of transport of chaperones into the bacteria grown in the presence of the respective compounds for $4 \mathrm{~h}$. The bacterial pellets were washed three times in $1 \times$ phosphate-buffered saline (PBS), PBS excess was aspirated by pipette tip, and wet pellets were weighted; extracts were then prepared as mentioned above. Intracellular concentration of betaine was determined by modification of liquid chromatography tandem mass spectrometry (LC-MS/MS) on hydrophilic interaction liquid chromatography high-performance liquid chromatography (HILICHPLC) column by a previously published method (Holm et al. 2003). Serine was measured by LC-MS/MS using commercially a available kit for amino acid analysis (EZ:faast, Phenomenex, Torrance, CA, USA). SAM was measured by LC-MS/MS utilizing a Hypercarb column filled with porous graphitic carbon stationary phase (Krijt et al. 2009). Concentration of glycerol was determined by gas chromatography MS (GC-MS) after solvent extraction used to analyze urinary organic acid (Chalmers and Lawson 1982). Intracellular taurine was measured by an amino acid analyzer AAA 400 (Ingos, Czech Republic) using cation-exchange chromatography with postcolumn ninhydrin derivatization.

\section{Expression in E. coli}

The wild-type CBS and mutant constructs were derived from the pHCS3-expression plasmid (Kožich and Kraus 1992). Seven mutant plasmids, namely, c.341 C $>$ T (p.A114V), c.442 G>A (p.G148R), c.526 G>A (p.E176K), c.1224-2 $\mathrm{A}>\mathrm{C}$ (r.1224_1358del; p.W409_G453del), c.1265 C $>\mathrm{T}$ (p. P422L), c.1304 T>C (p.I435T), and c.1397 C $>\mathrm{T}$ (p.S466L) were prepared using the previously described procedure of replacing a fragment of wild-type CBS expression plasmid with the equivalent restriction fragment derived from the mutant patient-derived complementary DNA (cDNA) (Kožich and Kraus 1992). The remaining mutations were introduced into the wild-type expression plasmid with the help of the GeneTailor Site-directed mutagenesis kit (Invitrogen, Carlsbad, CA, USA) according to the manufacturer's procedure. The authenticity of all constructs was verified by dideoxy sequencing using ALF sequencer (Amersham Pharmacia Biotech, Piscataway, NJ, USA). Mutants were expressed in E. coli strain DH5- $\alpha$ at $37^{\circ} \mathrm{C}$ for $4 \mathrm{~h}$ after addition of $0.3 \mathrm{mM}$ isopropyl thiogalactoside (IPTG) to super optimal broth (SOB) medium at $\mathrm{OD}_{600} \sim 0.5-0.6$, and bacterial extracts were obtained after sonication, as described previously (Kožich and Kraus 1992). Total protein was determined by Lowry method using bovine serum albumin (BSA) as a standard (Lowry et al. 1951). Each mutation was expressed in parallel in the absence and presence of each chaperone, which was added at the time of IPTG induction.

Specific activity of mutants

First, specific activity of all mutants to synthesize cystathionine was measured by radiometric assay using $\left[{ }^{14} \mathrm{C}\right]$ serine as a substrate (Kožich and Kraus 1992). The product- $\left[{ }^{14} \mathrm{C}\right]$ cystathionine - was separated using paper chromatography and detected by scintillation (Kraus 1978). Subsequently, specific activity of the chaperone-responsive mutants (increase in the specific activity of the enzyme by $>30 \%$ ) was determined by a more sensitive LC-MS/MS method in both lysates from the first experiment and from the additional independent expression study. CBS activity was assayed at $10 \mathrm{mM}$ homocysteine and $10 \mathrm{mM}$ serine by the standard procedure, with incubation at $37^{\circ} \mathrm{C}$ for $2 \mathrm{~h}$ (Kožich and Kraus 1992) with the following modification: mixture 
of unlabeled and ${ }^{14} \mathrm{C}$-labeled serine was replaced by $10 \mathrm{mM}$ 2,3,3- ${ }^{2} \mathrm{H}$-labeled serine (Cambridge Isotope Laboratories), and the amount of 2,3,3- ${ }^{2} \mathrm{H}$-labeled cystathionine produced was determined by LC-MS/MS using a commercially available kit for amino acid analysis (EZ:faast, Phenomenex (Krijt et al, unpublished).

Native polyacrylamide gel electrophoresis and Western blot

As a surrogate marker of the tendency of mutants to misfold, we examined their quaternary structure in crude bacterial extracts. To assess the oligomeric structure, we used electrophoresis in gradient polyacrylamide gels under nondenaturing conditions, followed by Western blotting. Bacterial extracts containing $15 \mu \mathrm{g}$ of total protein were subjected to electrophoresis under nondenaturing conditions using Laemmli buffer system without sodium dodecyl sulfate (SDS) and with NuPAGE ${ }^{\circledR}$ Novex 3-8\% Trisacetate midi gel (Invitrogen) at $15 \mathrm{~mA}$ per gel. Proteins were transferred to polyvinylidene fluoride (PVDF) membrane by semidry blotting system, as described previously (Janosik et al. 2001b). CBS was detected by purified chicken anti-hCBS serum H19 (HenA, Czech Republic) followed by stabilized rabbit anti-chicken horseradish-peroxidaseconjugated antibody (Pierce, Rockford, IL, USA). In our previous study, we demonstrated that in our electrophoretic system, the wild-type CBS is present predominantly in the form of tetramers and in small amounts as octamers, dodecamers, and hexadecamers (Kožich et al. 2010). Signals of these correctly assembled CBS tetramers/oligomers that present as sharply demarcated fractions were obtained in this study by chemiluminescence (SuperSignal West Femto Chemiluminescence Substrate, Pierce, Rockford, IL, USA) employing the ChemiGenius station and GeneTools software for quantification (Janosik et al. 2001b).

\section{Results}

Transport of chaperones into E. coli

Efficient transport of chaperones across the E. coli cytoplasmic membrane and their intracellular retention are necessary conditions for studying their effects on CBS mutants. Intracellular concentrations of betaine, taurine, and glycerol increased significantly after 4-h growth of $E$. coli in the presence of these compounds in the medium, demonstrating their efficient uptake and retention by prokaryotic cells (see Table 1). It can be stipulated that $\delta$ ALA was also transported, as: (1) its transport system in E. coli exists and has already been characterized (Verkamp et al. 1993), and (2) it was shown previously that addition of $0.3 \mathrm{mM} \delta$-ALA to the medium increased heme content in the bacteria up to 50-fold (Kery et al. 1994). In contrast, we detected no increase in serine and SAM concentration after addition to the medium, and we excluded them from further studies. However, it cannot be ruled out that these two metabolites were transported efficiently but were released from the cells during harvesting.

\section{Effect of chaperones on structure and function of CBS} mutants

Effect of $\delta$-ALA The role of heme in CBS folding has been previously implicated, and impaired heme binding of CBS mutants has been proposed to be a common pathogenic mechanism in CBS deficiency (Janosik et al. 2001b; Majtan et al. 2008; Ojha et al. 2002). It was also shown that the heme precursor $\delta$-ALA increases heme saturation and yield of the wild-type human CBS expressed in E. coli (Kery et al. 1995). In our study, the coexpressional presence of $0.5 \mathrm{mM} \delta$-ALA improved oligomerization of 14 mutants, with an increase in

Table 1 Intracellular concentrations of chemical chaperones and cystathionine $\beta$-synthase (CBS) ligands after 4-h exposure to Escherichia coli

\begin{tabular}{|c|c|c|c|}
\hline \multicolumn{2}{|c|}{ Chaperones and ligands in SOB medium } & \multicolumn{2}{|c|}{ Chaperones and ligands in E. coli, $\mathrm{mmol} / \mathrm{kg}$ wet weigh } \\
\hline & & - Addition & + Addition \\
\hline \multirow[t]{3}{*}{ Chaperones } & Glycerol $750 \mathrm{mmol} / \mathrm{l}$ & 2.3 & 64.6 \\
\hline & Betaine $100 \mathrm{mmol} / \mathrm{l}$ & 0.4 & 11.0 \\
\hline & Taurine $50 \mathrm{mmol} / 1$ & $\mathrm{ND}^{\mathrm{a}}$ & 8.4 \\
\hline \multirow[t]{3}{*}{ CBS ligands } & $\delta$-ALA $0.5 \mathrm{mmol} / \mathrm{l}^{\mathrm{b}}$ & Not measured & \\
\hline & L-serine $100 \mathrm{mmol} / \mathrm{l}$ & $\mathrm{ND}^{\mathrm{a}}$ & $\mathrm{ND}^{\mathrm{a}}$ \\
\hline & $\mathrm{SAM} 1 \mathrm{mmol} / 1$ & 0.05 & 0.05 \\
\hline
\end{tabular}

$S O B$ super optimal broth, $\delta$ - $A L A \delta$-aminolevulinic acid, SAM S-adenosyl-L-methionine

${ }^{\mathrm{a}} N D$ Not detected, below the detection limit $-0.02 \mathrm{mmol} / \mathrm{kg}$ E. coli wet weight for taurine, $0.01 \mathrm{mmol} / \mathrm{kg}$ E. coli wet weight for serine

${ }^{\mathrm{b}}$ Concentrations of $\delta$-ALA were not determined, as it was shown previously that addition of $0.3 \mathrm{mM} \delta$-ALA to the growth medium increased heme content in the bacteria up to 50-fold (Kery et al. 1994). 
Fig. 1 Effect of $\delta$ -

aminolevulinic acid ( $\delta$-ALA), betaine, glycerol, and taurine on oligomerization of 27 cystathionine $\beta$-synthase (CBS) mutants. Crude extracts $-15 \cdot \mathrm{g}$ total protein - obtained from the cells grown in the absence (odd lanes) and presence (even lanes) of chaperone were examined for the presence of CBS tetramers/oligomers by native polyacrylamide gel electrophoresis (PAGE) and Western blot with immunodetection. Correctly assembled CBS tetramers (arrows) and higher-order oligomers (octamers, dodecamers, hexadecamers) are present as sharply demarcated fractions. Mutants responding to chaperones by formation of increased amounts of correctly assembled CBS molecules are shown in boxes

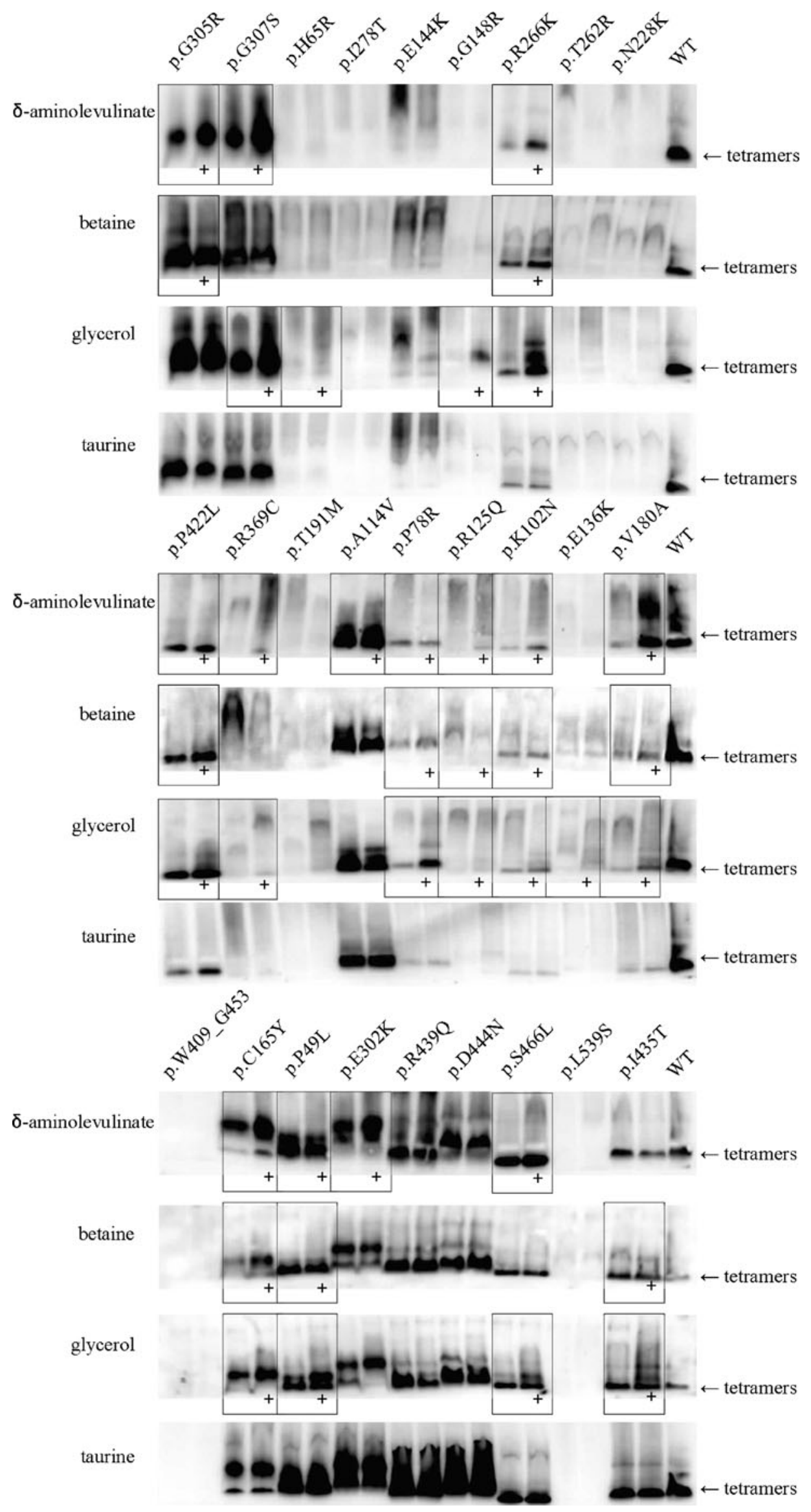


the amount of tetramers up to 8.9-fold (see Fig. 1 and Table 2); 11 of the responsive mutants also showed a simultaneous increase in specific activity up to 4.1 -fold (see Fig. 2 and Table 3), whereas activity of three mutantsp.G305R, p.G307S, and p.C165Y - did not rise. Responsive mutants are located in the regulatory domain (p.P422L, p.S466L), at the dimer-dimer interface (p.A114V, p.V180A, p.P78R), or in other locations of the active core (p.P49L, p.E302K, p.C165Y, p.R125Q, p.K102N, p.R369C). The effect of $\delta$-ALA on two mutations in the heme-binding pocket differed substantially. Whereas oligomerization and activity of the p.R266K was dramatically rescued, the p.H65R did not exhibit any changes after $\delta$-ALA treatment.

Effect of betaine Betaine is a naturally occurring osmolyte in which thermo- and osmoprotective properties are well known
(Caldas et al. 1999; Perroud and Le Rudulier 1985). As a methyl donor, betaine facilitates remethylation of homocysteine to methionine and is widely used to treat CBS deficiency (Lawson-Yuen and Levy 2006). Similar results as in $\delta$-ALA experiments were observed after $100 \mathrm{mM}$ betaine treatment, but the effects were weaker. Eleven mutants (p.P49L, p.C165Y, p.R125Q, p.K102N, p.R369C, p.V180A, p.P78R, p.S466L, p.I435T, p.G305R, p.R266K) exhibited an increase in the amount of correctly folded tetramers up to 1.8 -fold (see Fig. 1 and Table 2), which was - with the exception of p.G305R and p.C165Y - accompanied by an increase in the catalytic activity of up to 1.6-fold (see Fig. 2 and Table 3).

Effect of glycerol Glycerol belongs to osmotically active polyols, and its properties as a general chemical chaperone have been demonstrated by many studies (Brown et al.

Table 2 Effects of $\delta$-ALA, betaine, glycerol and taurine on amounts of tetramers/oligomers of 27 CBS mutants

\begin{tabular}{|c|c|c|c|c|c|c|c|c|c|}
\hline \multirow[t]{2}{*}{ topology of the mutants } & \multirow[t]{2}{*}{ mutants } & \multicolumn{2}{|l|}{$\delta$-ALA } & \multicolumn{2}{|l|}{ betaine } & \multicolumn{2}{|c|}{ glycerol } & \multicolumn{2}{|l|}{ taurine } \\
\hline & & $0 \mathrm{mM}$ & $0.5 \mathrm{mM}$ & $0 \mathrm{mM}$ & $100 \mathrm{mM}$ & $0 \mathrm{mM}$ & $750 \mathrm{mM}$ & $0 \mathrm{mM}$ & $50 \mathrm{mM}$ \\
\hline \multirow[t]{13}{*}{ buried mutants } & p.G305R & $213.4^{\mathrm{a}}$ & $277.8^{\mathrm{a}}$ & $137.2^{\mathrm{a}}$ & $187.2^{\mathrm{a}}$ & 276.6 & 264.8 & 199.8 & 237.8 \\
\hline & p.G307S & $250.2^{\mathrm{a}}$ & $311.9^{\mathrm{a}}$ & 230.2 & 226.4 & $102.5^{\mathrm{a}}$ & $143.1^{\mathrm{a}}$ & 258.7 & 253.3 \\
\hline & p.P422L & $86.0^{\mathrm{a}}$ & $100.5^{\mathrm{a}}$ & 28.2 & 27.2 & $23.5^{\mathrm{a}}$ & $47.3^{\mathrm{a}}$ & 19.0 & 20.0 \\
\hline & p.I278T & N.D. & N.D. & N.D. & N.D. & N.D. & N.D. & N.D. & N.D. \\
\hline & p.E144K & N.D. & N.D. & N.D. & N.D. & N.D. & N.D. & N.D. & N.D. \\
\hline & p.G148R & N.D. & N.D. & N.D. & N.D. & $1.9^{\mathrm{a}}$ & $20.8^{\mathrm{a}}$ & N.D. & N.D. \\
\hline & p.R266K & $28.7^{\mathrm{a}}$ & $65.8^{\mathrm{a}}$ & $15.0^{\mathrm{a}}$ & $19.3^{\mathrm{a}}$ & $11.8^{\mathrm{a}}$ & $28.6^{\mathrm{a}}$ & 11.1 & 8.4 \\
\hline & p.T262R & N.D. & N.D. & N.D. & N.D. & N.D. & N.D. & N.D. & N.D. \\
\hline & p.N228K & N.D. & N.D. & N.D. & N.D. & N.D. & N.D. & N.D. & N.D. \\
\hline & p.L539S & N.D. & N.D. & N.D. & N.D. & N.D. & N.D. & N.D. & N.D. \\
\hline & p.W409_G453del & N.D. & N.D. & N.D. & N.D. & N.D. & N.D. & N.D. & N.D. \\
\hline & p.C165Y & $152.3^{\mathrm{a}}$ & $270.2^{\mathrm{a}}$ & $112.4^{\mathrm{a}}$ & $155.7^{\mathrm{a}}$ & $125.3^{\mathrm{a}}$ & $172.3^{\mathrm{a}}$ & 100.5 & 109.9 \\
\hline & p.S466L & $133.0^{\mathrm{a}}$ & $199.0^{\mathrm{a}}$ & 47.1 & 55.0 & $53.4^{\mathrm{a}}$ & $74.9^{\mathrm{a}}$ & 88.7 & 81.8 \\
\hline \multirow[t]{15}{*}{ solvent accessible mutants } & p.H65R & N.D. & N.D. & N.D. & N.D. & $4.6^{\mathrm{a}}$ & $18.8^{\mathrm{a}}$ & N.D. & N.D. \\
\hline & p.R369C & $9.7^{\mathrm{a}}$ & $47.7^{\mathrm{a}}$ & $17.7^{\mathrm{a}}$ & $19.7^{\mathrm{a}}$ & $10.9^{\mathrm{a}}$ & $19.4^{\mathrm{a}}$ & 19.1 & 17.8 \\
\hline & p.T191M & N.D. & N.D. & N.D. & N.D. & N.D. & N.D. & N.D. & N.D. \\
\hline & p.A114V & $127.3^{\mathrm{a}}$ & $207.5^{\mathrm{a}}$ & 69.6 & 59.2 & 113.4 & 130.2 & 127.0 & 115.9 \\
\hline & p.P78R & $45.9^{\mathrm{a}}$ & $72.6^{\mathrm{a}}$ & $7.2^{\mathrm{a}}$ & $13.1^{\mathrm{a}}$ & $9.7^{\mathrm{a}}$ & $34.0^{\mathrm{a}}$ & 4.2 & 4.2 \\
\hline & p.R125Q & $7.3^{\mathrm{a}}$ & $64.2^{\mathrm{a}}$ & $6.4^{\mathrm{a}}$ & $13.6^{\mathrm{a}}$ & $15.1^{\mathrm{a}}$ & $22.9^{\mathrm{a}}$ & 6.5 & 7.8 \\
\hline & p.K102N & $24.2^{\mathrm{a}}$ & $45.4^{\mathrm{a}}$ & $6.5^{\mathrm{a}}$ & $9.3^{\mathrm{a}}$ & $8.4^{\mathrm{a}}$ & $22.7^{\mathrm{a}}$ & 12.6 & 15.6 \\
\hline & p.E176K & 5.8 & 2.2 & 13.7 & 14.2 & $12.6^{\mathrm{a}}$ & $29.2^{\mathrm{a}}$ & 7.3 & 6.8 \\
\hline & p.V180A & $41.9^{\mathrm{a}}$ & $76.6^{\mathrm{a}}$ & $11.6^{\mathrm{a}}$ & $16.2^{\mathrm{a}}$ & $12.5^{\mathrm{a}}$ & $30.9^{\mathrm{a}}$ & 20.6 & 19.9 \\
\hline & p.I435T & 72.3 & 50.9 & $76.4^{\mathrm{a}}$ & $109.8^{\mathrm{a}}$ & $125.8^{\mathrm{a}}$ & $186.8^{\mathrm{a}}$ & 109.1 & 96.7 \\
\hline & p.P49L & $224.3^{\mathrm{a}}$ & $256.0^{\mathrm{a}}$ & $160.0^{\mathrm{a}}$ & $198.2^{\mathrm{a}}$ & $88.2^{\mathrm{a}}$ & $109.3^{\mathrm{a}}$ & 156.1 & 163.1 \\
\hline & p.E302K & $175.8^{\mathrm{a}}$ & $233.8^{\mathrm{a}}$ & 247.5 & 213.2 & 234.1 & 218.0 & 187.4 & 182.8 \\
\hline & p.R439Q & 148.2 & 153.5 & 219.1 & 247.3 & 329.2 & 233.1 & 189.4 & 204.8 \\
\hline & p.D444N & 180.1 & 208.4 & 261.0 & 297.8 & 377.6 & 350.8 & 291.0 & 300.5 \\
\hline & wild-type CBS & $100.0^{\mathrm{a}}$ & $110.2^{\mathrm{a}}$ & $100.0^{\mathrm{a}}$ & $109.3^{\mathrm{a}}$ & $100.0^{\mathrm{a}}$ & $120.6^{\mathrm{a}}$ & $100.0^{\mathrm{a}}$ & $105.4^{\mathrm{a}}$ \\
\hline
\end{tabular}

$N D$ not detected, signal of CBS antigen on Western blot below the signal of negative control

${ }^{a}$ Signals of responsive mutants $(>30 \%)$ and wild-type expressed as percent of signal of wild-type CBS as a mean of two independent experiments 
1996; Kim et al. 2006; Meng et al. 2001; Sato et al. 1996; Tamarappoo and Verkman 1998). Fifteen mutants showed an increased amount of correctly assembled protein up to 11.2-fold (see Fig. 1 and Table 2). In 12 of them, we also observed increased specific activity up to 6.6-times (see Fig. 2 and Table 3). Glycerol restored specific activity and/ or tetramer assembly of three additional mutants that were not rescued by $\delta$-ALA or betaine-p.G148R, p.E176K, and p.H65R. The effect of glycerol on enhancing the assembly of CBS subunits can also be demonstrated by the appearance of higher-order oligomers (see additional upper bands in Fig. 1), as also shown in other studies (Shelanski et al. 1973).

Effect of taurine Taurine is an amino acid with many physiological functions, including osmotic activity (Huxtable 1992). Taurine levels in CBS-deficient patients are decreased, which has been proposed to possibly contribute to the clinical complications of homocystinuria (Mafrici 2005). We examined the properties of mutants expressed in $50 \mathrm{mM}$ taurine, but no effect on the amount of oligomers and/or activity was observed (see Tables 2 and 3), although taurine was efficiently transported into the cells (see Table 1).

Effect of chaperones on steady-state levels of CBS polypeptides

The above-described CBS mutants exhibited increased steadystate levels of correctly assembled tetramers after chaperone treatment. We examined whether this increase of tetramers originated from shifted proportion between correctly assembled and misassembled molecules or whether they resulted from an increased amount of total CBS. Therefore we analyzed the amounts of total CBS signal containing both the correctly assembled water-soluble as well as misfolded water-insoluble fractions by boiling uncentrifuged cell lysates in 3\% SDS at $100^{\circ} \mathrm{C}$ for $10 \mathrm{~min}$. Extracts were than subjected to SDS-PAGE followed by Western blotting. No significant differences of total SDS-soluble CBS antigen in samples grown in the absence and presence of chaperones were observed (data not
Fig. 2 Effect of $\delta$ aminolevulinic acid ( $\delta$-ALA), betaine, and glycerol on specific activity of responsive cystathionine $\beta$-synthase (CBS) mutants. Effects are expressed as increases in specific activity as percentage of signal of wild-type CBS $(100 \%$ corresponds to specific activity of wild-type CBS expressed without presence of chaperone). Data were obtained by sensitive liquid chromatography tandem mass spectrometry (LC-MS/MS) and are presented as a mean from two independent expressions
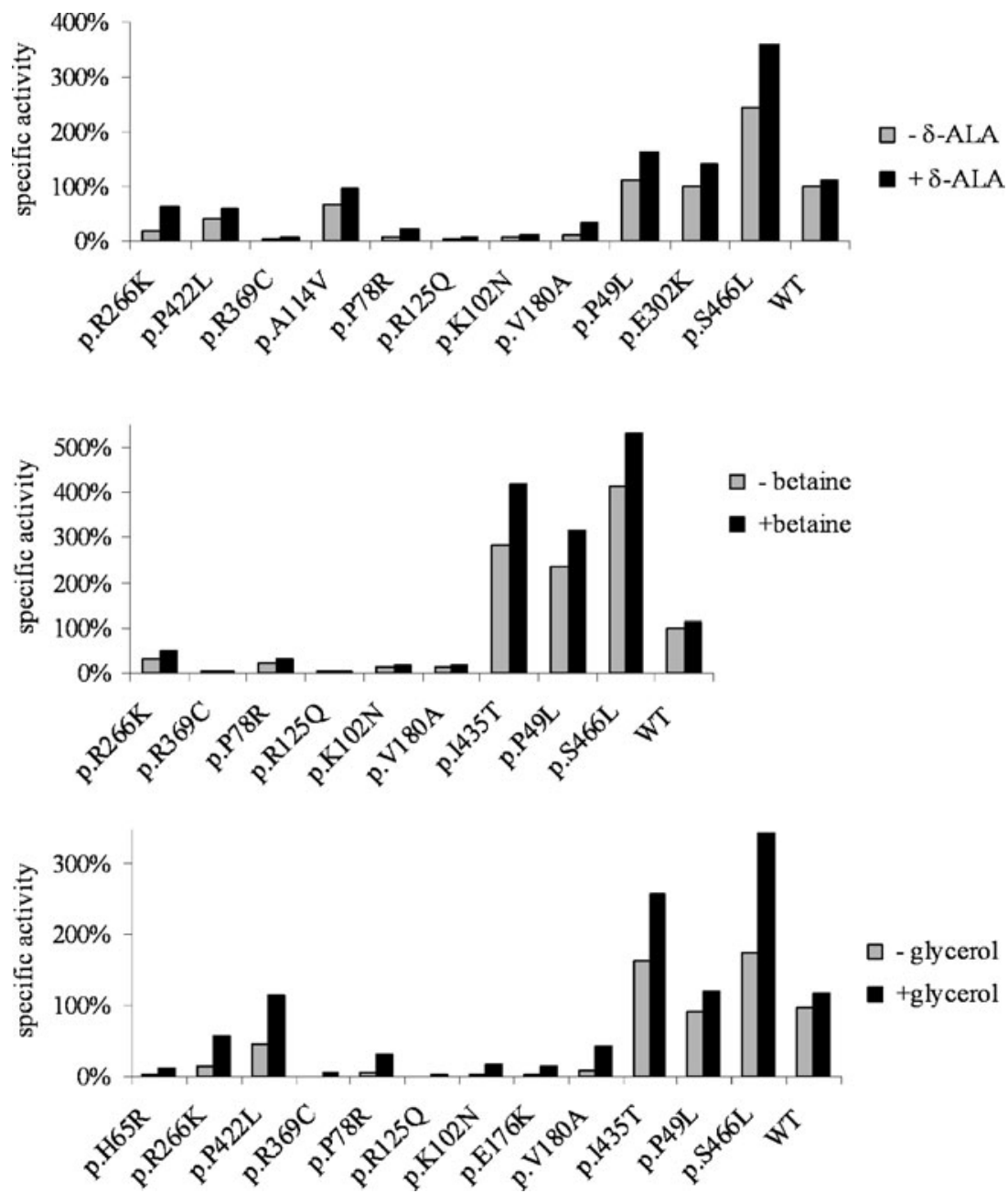
Table 3 Effects of $\delta$-aminolevulinic acid ( $\delta$-ALA), betaine, glycerol, and taurine on specific activity of 27 cystathionine $\beta$-synthase (CBS) mutants

\begin{tabular}{|c|c|c|c|c|c|c|c|c|c|}
\hline \multirow[t]{2}{*}{ topology of the mutants } & \multirow[t]{2}{*}{ mutants } & \multicolumn{2}{|l|}{$\delta$-ALA } & \multicolumn{2}{|l|}{ betaine } & \multicolumn{2}{|c|}{ glycerol } & \multicolumn{2}{|l|}{ taurine } \\
\hline & & $0 \mathrm{mM}$ & $0.5 \mathrm{mM}$ & $0 \mathrm{mM}$ & $100 \mathrm{mM}$ & $0 \mathrm{mM}$ & $750 \mathrm{mM}$ & $0 \mathrm{mM}$ & $50 \mathrm{mM}$ \\
\hline \multirow[t]{13}{*}{ buried mutants } & p.G305R & N.D. & N.D. & N.D. & N.D. & N.D. & N.D. & N.D. & N.D. \\
\hline & p.G307S & N.D. & N.D. & N.D. & N.D. & N.D. & N.D. & N.D. & N.D. \\
\hline & p.P422L & $43.4^{\mathrm{a}}$ & $65.0^{\mathrm{a}}$ & 48.4 & 63.2 & $61.4^{\mathrm{a}}$ & $150.0^{\mathrm{a}}$ & 61.7 & 64.0 \\
\hline & p.I278T & N.D. & N.D. & N.D. & N.D. & N.D. & N.D. & N.D. & N.D. \\
\hline & p.E144K & N.D. & N.D. & N.D. & N.D. & N.D. & N.D. & N.D. & N.D. \\
\hline & p.G148R & N.D. & N.D. & N.D. & N.D. & N.D. & N.D. & N.D. & N.D. \\
\hline & p.R266K & $19.5^{\mathrm{a}}$ & $66.1^{\mathrm{a}}$ & $21.7^{\mathrm{a}}$ & $33.8^{\mathrm{a}}$ & $17.1^{\mathrm{a}}$ & $76.1^{\mathrm{a}}$ & 48.7 & 51.0 \\
\hline & p.T262R & N.D. & N.D. & N.D. & N.D. & N.D. & N.D. & N.D. & N.D. \\
\hline & p.N228K & N.D. & N.D. & N.D. & N.D. & N.D. & N.D. & N.D. & N.D. \\
\hline & p.L539S & N.D. & N.D. & N.D. & N.D. & N.D. & N.D. & N.D. & N.D. \\
\hline & p.W409_G453del & N.D. & N.D. & N.D. & N.D. & N.D. & N.D. & N.D. & N.D. \\
\hline & p.C165Y & N.D. & N.D. & N.D. & N.D. & N.D. & N.D. & N.D. & N.D. \\
\hline & p.S466L & $260.5^{\mathrm{a}}$ & $382.5^{\mathrm{a}}$ & 280.5 & 360.0 & $229.5^{\mathrm{a}}$ & $453.0^{\mathrm{a}}$ & 226.0 & 173.6 \\
\hline \multirow[t]{15}{*}{ solvent accessible mutants } & p.H65R & N.D. & N.D. & N.D. & N.D. & $2.5^{\mathrm{a}}$ & $15^{\mathrm{a}}$ & N.D. & N.D. \\
\hline & p.R369C & $2.1^{\mathrm{a}}$ & $6.1^{\mathrm{a}}$ & $1.8^{\mathrm{a}}$ & $2.7^{\mathrm{a}}$ & $1.7^{\mathrm{a}}$ & $6.2^{\mathrm{a}}$ & 2.0 & 1.9 \\
\hline & p.T191M & N.D. & N.D. & N.D. & N.D. & N.D. & N.D. & N.D. & N.D. \\
\hline & p.A114V & $69.5^{\mathrm{a}}$ & $101.7^{\mathrm{a}}$ & 69.8 & 71.0 & 75.8 & 100.8 & 58.8 & 60.3 \\
\hline & p.P78R & $9.4^{\mathrm{a}}$ & $24.0^{\mathrm{a}}$ & $14.1^{\mathrm{a}}$ & $19.9^{\mathrm{a}}$ & $7.8^{\mathrm{a}}$ & $40.7^{\mathrm{a}}$ & 2.8 & 1.6 \\
\hline & p.R125Q & $2.0^{\mathrm{a}}$ & $8.1^{\mathrm{a}}$ & $2.6^{\mathrm{a}}$ & $3.3^{\mathrm{a}}$ & $1.5^{\mathrm{a}}$ & $4.1^{\mathrm{a}}$ & 6.8 & 2.7 \\
\hline & p.K102N & $8.4^{\mathrm{a}}$ & $11.7^{\mathrm{a}}$ & $9.9^{\mathrm{a}}$ & $12.7^{\mathrm{a}}$ & $5.5^{\mathrm{a}}$ & $21.9^{\mathrm{a}}$ & 9.2 & 6.8 \\
\hline & p.E176K & 8.6 & 8.5 & 1.5 & 1.5 & $2.7^{\mathrm{a}}$ & $17.5^{\mathrm{a}}$ & 7.3 & 6.8 \\
\hline & p.V180A & $12.4^{\mathrm{a}}$ & $35.2^{\mathrm{a}}$ & $9.0^{\mathrm{a}}$ & $12.0^{\mathrm{a}}$ & $13.0^{\mathrm{a}}$ & $55.7^{\mathrm{a}}$ & 25.8 & 26.8 \\
\hline & p.I435T & 132.1 & 135.7 & $174.6^{\mathrm{a}}$ & $191.0^{\mathrm{a}}$ & $215.3^{\mathrm{a}}$ & $340.3^{\mathrm{a}}$ & 205.8 & 177.3 \\
\hline & p.P49L & $119.5^{\mathrm{a}}$ & $172.5^{\mathrm{a}}$ & $158.5^{\mathrm{a}}$ & $214.5^{\mathrm{a}}$ & $119.0^{\mathrm{a}}$ & $158.5^{\mathrm{a}}$ & 92.8 & 94.0 \\
\hline & p.E302K & $107.0^{\mathrm{a}}$ & $152.0^{\mathrm{a}}$ & 78.4 & 82.6 & 140.7 & 137.7 & 134.9 & 153.0 \\
\hline & p.R439Q & 138.7 & 150.6 & 139.9 & 180.4 & 131.9 & 152.6 & 94.6 & 69.1 \\
\hline & p.D444N & 220.8 & 183.5 & 196.1 & 223.9 & 179.4 & 205.0 & 124.8 & 137.5 \\
\hline & wild type CBS & $107.4^{\mathrm{a}}$ & $118.0^{\mathrm{a}}$ & $135.1^{\mathrm{a}}$ & $150.2^{\mathrm{a}}$ & $129.3^{\mathrm{a}}$ & $153.2^{\mathrm{a}}$ & $111.7^{\mathrm{a}}$ & $109.0^{\mathrm{a}}$ \\
\hline
\end{tabular}

$N D$ not detected; activity below the limit of detection $[0.3 \mathrm{nmol} / \mathrm{mg} / \mathrm{h}$ for liquid chromatography tandem mass spectrometry (LC-MS/MS) and $1.5 \mathrm{nmol} / \mathrm{mg} / \mathrm{h}$ for radiometric assay, respectively]

${ }^{a}$ Specific activity of responsive mutants ( $\left.>30 \%\right)$ and wild-type CBS were determined by sensitive LC-MS/MS and expressed as a mean of two independent experiments (all mutants were measured once by the radiometric method); nmol cystathionine $/ \mathrm{mg}$ protein $/ \mathrm{h}$

shown). This experiment demonstrated that in the presence of chaperones, the total amounts of mutant enzymes did not rise and suggests that the increased tetrameric fractions originate from a shift in proportion between correctly assembled and misassembled molecules.

\section{Discussion}

Our study showed that two thirds of mutants in this study responded to the presence of either $0.5 \mathrm{mM} \delta$-ALA, $100 \mathrm{mM}$ betaine, and/or $750 \mathrm{mM}$ glycerol during expression by increased formation of correctly assembled tetramers. More importantly, this restoration of quaternary structure was in most cases accompanied by an increase in catalytic activity, with the exception of p.G305R, p.G307S, p.G148R, and p.C165Y. Mutation topology appears to be an important determinant of chaperone responsiveness. Eleven of 14 mutations located at the enzyme surface (i.e., solvent-accessible mutations) showed an increase in the amounts of tetramers as well as in the catalytic activity. In contrast, only six of 13 buried mutants formed more tetramers in the presence of chaperones. Moreover, raised levels of tetramers were not accompanied by restoration of the catalytic activity of p.G305R, p.G307S, and p.G148R, which are all located in the active site of the enzyme, and of the mutant p.C165Y. Our previous study showed that solvent-exposed mutations were more prone to rescue by 
lower temperature of expression (Kožich et al. 2010) and that their activity correlated significantly with the amount of tetramers. Both these studies strongly suggest that mutation topology may be an important determinant of responsiveness to therapeutic approaches aimed at correcting misfolding/misassembly of mutant subunits in CBS deficiency. However, detailed insight into the structurefunction relationships is beyond the scope of this paper, and will require purification and structural analysis of the mutants.

The chaperoning activity of tested compounds differed in both the number of rescuable mutants and the magnitude of effects; $\delta$-ALA and glycerol rescued an overlapping set of mutants, although their mechanisms of action are most likely different. Glycerol acts as a general osmolyte via interaction with protein backbone, resulting in globule stabilization by preferring hydration that favors the more compact native state over the denatured state (Gekko and Timasheff 1981; Mishra et al. 2007). In contrast, addition of $\delta$-ALA increases concentrations of CBS ligand, heme, the effect of which on mutant assembly has been discussed in previous studies (Janosik et al. 2001b; Majtan et al. 2008). This chaperoning activity of heme may be due to stabilization of a limited number of partially folded intermediates (Wittung-Stafshede 2002). It should be noted that only mutants with retained ability to bind heme can potentially be rescued by heme, whereas mutations affecting heme binding (such as p.H65R) result in nonresponsiveness to $\delta$-ALA. Betaine rescued a partially overlapping and smaller set of mutants, and its effect on oligomerization and activity was much weaker than that of $\delta$-ALA and glycerol. This as yet undescribed chaperoning effect of betaine may contribute to its well-known therapeutic efficacy in homocystinuria that is based on enhanced homocysteine remethylation via the betaine homocysteine methyltransferase.

Although the tested compounds improved oligomerization and activity of many mutants in E. coli, their possible therapeutic use requires additional considerations. It is unclear whether efficient concentrations of these compounds can be achieved in humans in vivo without eliciting side effects. Data on concentrations of glycerol and betaine that can be achieved in human tissues are not available, and only plasma levels of these compounds can be found in the literature. Plasma concentrations of glycerol observed in asymptomatic patients with glycerol kinase deficiency of $5 \mathrm{mM}$ (McCabe 2001) and peak concentration of plasma betaine after oral administration of $1.5 \mathrm{mM}$ (Schwahn et al. 2003) were one order of magnitude lower than the intracellular concentrations of these compounds observed in E. coli. Whereas administration of glycerol (Singh et al. 2007) and betaine (Schwahn et al. 2003) are safe, with no significant side effects even in relatively high concentra- tions, $\delta$-ALA is far from practical for use in humans because of its toxicity. Nevertheless, exploration of mechanisms by which heme rescues misfolded CBS enzyme molecules may facilitate a design of novel and possibly less toxic heme analogs.

Our study shows that patients with only certain genotypes may benefit from chaperone treatment. Fourteen chaperoneresponsive mutants represent 56 of 713 of known patientderived CBS alleles. Candidates for chaperone therapy are undoubtedly those mutants that responded to all three compounds, namely, p.R266K, p.P49L, p.R125Q, p.K102N, p.R369C, p.V180A, p.P78R, and p.S466L. It should be emphasized that p.R125Q, as well as p.H65R and p.E176Kboth rescuable by glycerol - are mutations present in difficultto-manage patients nonresponsive to $\mathrm{B}_{6}$ therapy. Considering the frequency of patient-derived mutations that may be responsive to chaperone treatment, our study indicates that this new therapeutic approach may become useful in about one tenth of patients with homocystinuria.

Acknowledgement The authors thank Lucia Krouská, MSc. and Zdeněk Č́nský, MSc. for metabolite analysis and Aleš Hnízda, MSc. for consultations. This work was supported by the Wellcome Trust International Senior Research Fellowship in Biomedical Science in Central Europe (reg.No 070255/Z/03/Z) and by a grant from the Grant Agency of Charles University No. 84507. Institutional support was provided by the Research Project of Charles University No. MSM20620806.

Open Access This article is distributed under the terms of the Creative Commons Attribution Noncommercial License which permits any noncommercial use, distribution, and reproduction in any medium, provided the original author(s) and source are credited.

\section{References}

Agorogiannis EI, Agorogiannis GI, Papadimitriou A, Hadjigeorgiou GM (2004) Protein misfolding in neurodegenerative diseases. Neuropathol Appl Neurobiol 30(3):215-224

Arakawa T, Ejima D, Kita Y, Tsumoto K (2006) Small molecule pharmacological chaperones: From thermodynamic stabilization to pharmaceutical drugs. Biochim Biophys Acta 64(11):16771687

Bolen DW, Baskakov IV (2001) The osmophobic effect: natural selection of a thermodynamic force in protein folding. J Mol Biol 310(5):955-963

Brown CR, Hong-Brown LQ, Biwersi J, Verkman AS, Welch WJ (1996) Chemical chaperones correct the mutant phenotype of the delta F508 cystic fibrosis transmembrane conductance regulator protein. Cell Stress Chaperones 1(2):117-125

Caldas T, Demont-Caulet N, Ghazi A, Richarme G (1999) Thermoprotection by glycine betaine and choline. Microbiology 145(Pt 9): 2543-2548

Chalmers RA, Lawson AM (1982) Organic acids in man. Chapman and Hall Ltd., London

Gaustadnes M, Ingerslev J, Rutiger N (1999) Prevalence of congenital homocystinuria in Denmark. N Engl J Med 340(19):1513 
Gekko K, Timasheff SN (1981) Mechanism of protein stabilization by glycerol: preferential hydration in glycerol-water mixtures. Biochemistry 20(16):4667-4676

Hayden MR, Tyagi SC, Kerklo MM, Nicolls MR (2005) Type 2 diabetes mellitus as a conformational disease. Jop 6(4):287-302

Holm PI, Ueland PM, Kvalheim G, Lien EA (2003) Determination of choline, betaine, and dimethylglycine in plasma by a highthroughput method based on normal-phase chromatographytandem mass spectrometry. Clin Chem 49(2):286-294

Huxtable RJ (1992) Physiological actions of taurine. Physiol Rev 72 (1):101-163

Janosik M, Kery V, Gaustandes M, Maclean KN, Kraus JP (2001a) Regulation of human cystathionine beta-synthase by S-adenosylL-methionine: evidence for two catalytically active conformations involving an autoinhibitory domain in the C-terminal region. Biochemistry 40(35):10625-10633

Janosik M, Oliveriusova J, Janosikova B, Sokoova J, Kraus E, Kraus JP, Kožich V (2001b) Impaired heme binding and aggregation of mutant cystathionine beta-synthase subunits in homocystinuria. Am J Hum Genet 68(6):1506-1513

Janosik M, Sokolova J, Janosikova B, Krijt J, Klatovska V, Kožich V (2009) Birth prevalence of homocystinuria in Central Europe: frequency and pathogenicity of mutation c.1105C $>$ T (p.R369C) in the cystathionine beta-synthase gene. J Pediatr 154(3):431-437

Kery V, Bukovska G, Kraus JP (1994) Transsulfuration depends on heme in addition to pyridoxal 5'-phosphate. Cystathionine betasynthase is a heme protein. J Biol Chem 269(41):25283-25288

Kery V, Elleder D, Kraus JP (1995) Delta-aminolevulinate increases heme saturation and yield of human cystathionine beta-synthase expressed in Escherichia coli. Arch Biochem Biophys 316(1):24-29

Kery V, Poneleit L, Kraus JP (1998) Trypsin cleavage of human cystathionine beta-synthase into an evolutionarily conserved active core: structural and functional consequences. Arch Biochem Biophys 355(2):222-232

Kim SH, Yan YB, Zhou HM (2006) Role of osmolytes as chemical chaperones during the refolding of aminoacylase. Biochem Cell Biol 84(1):30-38

Kožich V, Kraus JP (1992) Screening for mutations by expressing patient cDNA segments in E. coli: homocystinuria due to cystathionine beta-synthase deficiency. Hum Mutat 1(2):113-123

Kožich V, Kraus JP (2001) Homocysteine in health and disease. In: Carmel R, Jacobsen WJ (eds) Homocysteine in health and disease. Cambridge University Press, Cambridge, pp 223-244

Kožich V, Sokolová J, Klatovská V, Krijt J, Janošík M, Jelínek K, Kraus JP (2010) Cystathionine beta-synthase mutations: effect of mutation topology on folding and activity, Hum Mutat in press doi: 10.1002/humu.21273

Kraus J (1978) Purification and properties of cystathionine betasynthase from human liver. J Biol Chem 253(18):6523-6528

Krijt J, Duta A, Kožich V (2009) Determination of SAdenosylmethionine and S-Adenosylhomocysteine by LC-MS/ MS and evaluation of their stability in mice tissues. J Chromatogr B Analyt Technol Biomed Life Sci 877(22):2061-2066

Lawson-Yuen A, Levy HL (2006) The use of betaine in the treatment of elevated homocysteine. Mol Genet Metab 88(3):201-207

Lowry OH, Rosebrough NJ, Farr AL, Randall RJ (1951) Protein measurement with the Folin phenol reagent. J Biol Chem 193 (1):265-275

Mafrici B (2005) The contribution of low plasma taurine to clinical complications of Homocystinurea. Med Hypotheses 65(1):203-204

Majtan T, Singh LR, Wang L, Kruger WD, Kraus JP (2008) Active cystathionine beta-synthase can be expressed in heme-free systems in the presence of metal-substituted porphyrins or a chemical chaperone. J Biol Chem 283(50):34588-34595
McCabe ERB (2001) Disorders of glycerol metabolism. In: Scriver CR, Beaudet AL, Sly WS, Vale D, Childs B, Vogelstein B (eds) The metabolic and molecular bases of inherited disease, 7 th edn. McGraw-Hill, 1631-1652

Meier M, Janosik M, Kery V, Kraus JP, Burkhard P (2001) Structure of human cystathionine beta-synthase: a unique pyridoxal 5'-phosphate-dependent heme protein. EMBO J 20 (15):3910-3916

Meier M, Oliveriusova J, Kraus JP, Burkhard P (2003) Structural insights into mutations of cystathionine beta-synthase. Biochim Biophys Acta 1647(1-2):206-213

Meng F, Park Y, Zhou H (2001) Role of proline, glycerol, and heparin as protein folding aids during refolding of rabbit muscle creatine kinase. Int J Biochem Cell Biol 33(7):701-709

Mirkovic N, Marti-Renom MA, Weber BL, Sali A, Monteiro AN (2004) Structure-based assessment of missense mutations in human BRCA1: implications for breast and ovarian cancer predisposition. Cancer Res 64(11):3790-3797

Mishra R, Bhat R, Seckler R (2007) Chemical chaperone-mediated protein folding: stabilization of $\mathrm{P} 22$ tailspike folding intermediates by glycerol. Biol Chem 388(8):797-804

Mudd SH, Levy LH, Kraus JP (2001) Disorders of transsulfuration. In: Scriver CR, Beaudet AL, Sly WS, Vale D, Childs B, Vogelstein B (eds), The metabolic and molecular bases of inherited disease, 7th edn. McGraw-Hill. 1007-1056

Ojha S, Wu J, LoBrutto R, Banerjee R (2002) Effects of heme ligand mutations including a pathogenic variant, $\mathrm{H} 65 \mathrm{R}$, on the properties of human cystathionine beta-synthase. Biochemistry 41 (14):4649-4654

Pastores GM, Sathe S (2006) A chaperone-mediated approach to enzyme enhancement as a therapeutic option for the lysosomal storage disorders. Drugs R D 7(6):339-348

Perlmutter DH (2002) Chemical chaperones: a pharmacological strategy for disorders of protein folding and trafficking. Pediatr Res 52(6):832-836

Perroud B, Le Rudulier D (1985) Glycine betaine transport in Escherichia coli: osmotic modulation. J Bacteriol 161(1):393-401

Refsum H, Fredriksen A, Meyer K, Ueland PM, Kase BF (2004) Birth prevalence of homocystinuria. J Pediatr 144(6):830-832

Sato S, Ward CL, Krouse ME, Wine JJ, Kopito RR (1996) Glycerol reverses the misfolding phenotype of the most common cystic fibrosis mutation. J Biol Chem 271(2):635-638

Schwahn BC, Hafner D, Hohlfeld T, Balkenhol N, Laryea MD, Wendel U (2003) Pharmacokinetics of oral betaine in healthy subjects and patients with homocystinuria. Br J Clin Pharmacol 55(1):6-13

Shelanski ML, Gaskin F, Cantor CR (1973) Microtubule assembly in the absence of added nucleotides. Proc Natl Acad Sci U S A 70 (3): 765-768

Singh LR, Chen X, Kozich V, Kruger WD (2007) Chemical chaperone rescue of mutant human cystathionine beta-synthase. Mol Genet Metab 91(4):335-342

Skovby F, Kraus JP, Rosenberg LE (1984) Biosynthesis of human cystathionine beta-synthase in cultured fibroblasts. J Biol Chem 259(1):583-587

Tamarappoo BK, Verkman AS (1998) Defective aquaporin-2 trafficking in nephrogenic diabetes insipidus and correction by chemical chaperones. J Clin Invest 101(10):2257-2267

Verkamp E, Backman VM, Bjornsson JM, Soll D, Eggertsson G (1993) The periplasmic dipeptide permease system transports 5-aminolevulinic acid in Escherichia coli. J Bacteriol 175 (5):1452-1456

Wittung-Stafshede P (2002) Role of cofactors in protein folding. Acc Chem Res 35(4):201-208 